\title{
Prevalence and Correlates of DSM-IV Mental Disorders in South Korean Adults: The Korean Epidemiologic Catchment Area Study 2011
}

\author{
Maeng Je Cho ${ }^{1,2} \otimes$, Su Jeong Seong ${ }^{1,3}$, Jee Eun Park ${ }^{1,2}$, In-Won Chung ${ }^{4}$, Young Moon Lee ${ }^{5}$, \\ Ahn $\mathrm{Bae}^{6}$, Joon Ho Ahn ${ }^{7}$, Dong-Woo Lee ${ }^{8}$, Jae Nam Bae ${ }^{9}$, Seong-Jin Cho ${ }^{10}$, Jong-lk Park ${ }^{11}$, \\ Jungwoo Son ${ }^{12}$, Sung Man Chang ${ }^{13}$, Bong-Jin Hahm ${ }^{1,2}$, Jun-Young Lee ${ }^{1,14}$, Jee Hoon Sohn ${ }^{1,2}$, \\ Jin Sun Kim ${ }^{15}$, and Jin Pyo Hong ${ }^{16}$ \\ ${ }^{1}$ Department of Psychiatry and Behavioral Science, College of Medicine, Seoul National University, Seoul, Republic of Korea \\ ${ }^{2}$ Department of Neuropsychiatry, Seoul National University Hospital, Seoul, Republic of Korea \\ ${ }^{3}$ Department of Neuropsychiatry, Seoul National University Bundang Hospital, Seongnam, Republic of Korea \\ ${ }^{4}$ Department of Neuropsychiatry, Dongguk University International Hospital, Goyang, Republic of Korea \\ ${ }^{5}$ Department of Psychiatry, Gongju National Hospital, Gongju, Republic of Korea \\ ${ }^{6}$ Department of Psychiatry, Kwangju National Hospital, Gwangju, Republic of Korea \\ ${ }^{7}$ Department of Psychiatry, College of Medicine, University of Ulsan, Ulsan, Republic of Korea \\ ${ }^{8}$ Department of Psychiatry, Sanggye Paik Hospital, College of Medicine, Inje University, Seoul, Republic of Korea \\ ${ }^{9}$ Department of Psychiatry, College of Medicine, Inha University, Incheon, Republic of Korea \\ ${ }^{10}$ Department of Psychiatry, Gachon Medical School, Gachon University of Medicine and Science, Incheon, Republic of Korea \\ ${ }^{11}$ Department of Psychiatry, College of Medicine, Kangwon National University, Chuncheon, Republic of Korea \\ ${ }^{12}$ Department of Psychiatry, College of Medicine, Chungbuk National University, Cheongju, Republic of Korea \\ ${ }^{13}$ Department of Psychiatry, School of Medicine, Kyungpook National University, Daegu, Republic of Korea \\ ${ }^{14}$ Department of Neuropsychiatry, Seoul Metropolitan Boramae Medical Center, Seoul, Republic of Korea \\ ${ }^{15}$ Department of Psychiatry, Samjung Hospital, Incheon, Republic of Korea \\ ${ }^{16}$ Department of Psychiatry, Samsung Medical Center, Seoul, Republic of Korea
}

Objective The aim of this study was to estimate the prevalence and correlates of mental disorders in Korean adults.

Methods Door to door household surveys were conducted with community residents aged 18-74 years from July 19, 2011, to November 16, 2011 ( $n=6,022$, response rate 78.7\%). The sample was drawn from 12 catchment areas using a multistage cluster method. Each subject was assessed using the Korean version of the World Health Organization Composite International Diagnostic Interview (CIDI) based on the Diagnostic and Statistical Manual of Mental Disorders, Fourth Edition (DSM-IV).

Results Lifetime and 12-month prevalence estimates were as follows: alcohol use disorders, $13.4 \%$ and $4.4 \%$, respectively; nicotine use disorders, $7.2 \%$ and $4.0 \%$, respectively; anxiety disorders, $8.7 \%$ and $6.8 \%$, respectively; and mood disorders, $7.5 \%$ and $3.6 \%$, respectively. The prevalence rates of all types of DSM-IV mental disorders were $27.6 \%$ and $16.0 \%$, respectively. Being female; young; divorced, separated, or widowed; and in a low-income group were associated with mood and anxiety disorders after adjustment for various demographic variables, whereas being male and young were associated with alcohol use disorders. Higher income was not correlated with alcohol use disorder as it had been in the 2001 survey.

Conclusion The rate of depressive disorders has increased since 2001 (the first national survey), whereas that of anxiety disorders has been relatively stable. The prevalence of nicotine and alcohol use disorders has decreased, and the male-to-female ratio of those with this diagnosis has also decreased.

Psychiatry Investig 2015;12(2):164-170

Key Words Korean adults, Mental disorders, CIDI, Prevalence.

Received: April 1, 2014 Revised: June 11,2014 Accepted: June 11, 2014 Available online: February 2, 2015

$\triangle$ Correspondence: Maeng Je Cho, $\mathrm{MD}, \mathrm{PhD}$

Department of Psychiatry and Behavioral Science, Seoul National University College of Medicine, 101 Daehak-ro, Jongno-gu, Seoul 110-744, Republic of Korea Tel: +82-2-2072-3155, Fax: +82-2-744-7241, E-mail: mjcho@snu.ac.kr

(a) This is an Open Access article distributed under the terms of the Creative Commons Attribution Non-Commercial License (http://creativecommons.org/licenses/by-nc/3.0) which permits unrestricted non-commercial use, distribution, and reproduction in any medium, provided the original work is properly cited. 


\section{INTRODUCTION}

Epidemiological surveys can provide basic information on the progress, treatment, and long-term prognosis of disorders. ${ }^{1}$ Data from community-based epidemiological studies are especially important in psychiatry because information obtained from national insurance claim forms is not sufficient to evaluate the prevalence and distribution of mental disorders given that the lifetime treatment rate of mental disorders is as low as $15.7 \%^{1}$ in Korea. Thus, data from national insurance forms represent only a small portion of the entire target population.

The most recent nationwide epidemiological studies on mental disorders in Korea were the 2006 Korean Epidemiologic Catchment Area study Replication (KECA-R) ${ }^{1}$ and the 2001 Korean Epidemiologic Catchment Area study (KECA). ${ }^{2}$ The KECA and KECA-R used the Korean version of the Composite International Diagnostic Interview 2.1 (K-CIDI $2.1)^{3}$ to evaluate mental disorders based on the Diagnostic and Statistical Manual of Mental Disorders-fourth edition (DSM-IV). ${ }^{4}$ Comparisons of the results of these two studies revealed that the prevalence of mental disorders changed considerably during the 5 years between 2001 and 2006. The lifetime prevalence of nicotine and alcohol use disorders markedly decreased, from $23.5 \%$ in 2001 to $16.4 \%$ in 2006 . In contrast, the lifetime prevalence of major depressive disorder (MDD) increased, from $4.3 \%$ in 2001 to $5.6 \%$ in $2006 .{ }^{1,2}$

Korean society has experienced rapid change during past a few decades, and mental health problems such as suicide have emerged as social issues. Consequently, we need a new national survey to evaluate changes in mental illnesses since 2006. This study, conducted with the support of the Korea Ministry of Health and Welfare, estimated the prevalence and correlates of mental disorders in Korean adults and compared these results with those from previous studies.

\section{METHODS}

\section{Subjects}

The 2011 Korean Epidemiologic Catchment Area study (KECA-2011) is a nationally representative survey on mental illness conducted between July 19, 2011, and November 16, 2011. The target population included all non-institutionalized eligible Koreans aged $18^{-74}$. This is the first national survey on mental disorders to include individuals older than 65 years.

We used a multistage, cluster sampling method based on 2010 Population Census data obtained from the Korea National Statistical Office. ${ }^{5}$ We initially divided South Korea into six large divisions according to administrative districts. We then selected 12 catchment areas (Si/Gun/Gu in Korean) in these divisions based on population size and accessibility to research centers. Next, between three and eight subdivisions (Eup/Myeon/Dong) per catchment area were selected based on population size. We adopted the census blocks used in the

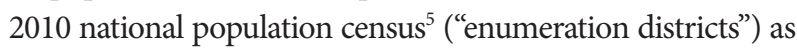
sampling units. A total of 246 sampling units were selected from within the total of 61 subdivisions. Every household in each unit was included in the survey (14,204 households), and one individual per household was randomly chosen as the respondent. Trained field workers conducted preliminary surveys by visiting every household to compile a list of eligible subjects. Household visits were repeated at least five times to contact individuals who were temporarily unavailable. We excluded individuals who were not within the age range, whose eligibility could not be ascertained, and who were impossible to contact. Houses that were not households and empty houses were also excluded.

All subjects were fully informed about the aims and methods of the study before completing the interview, and informed consent was obtained prior to participation. This study was approved by the Institutional Review Board of Seoul National University Hospital (IRB No. C-1104-092-359).

\section{Diagnostic assessment}

The Korean version of the Composite International Diagnostic Interview 2.1 (K-CIDI 2.1) was administered to all subjects by trained interviewers. The $\mathrm{CIDI}^{6}$ is a fully structured interview designed to identify psychiatric diagnoses. Although the $\mathrm{CIDI}^{6}$ can identify both ICD-10 diagnoses and DSM-IV ${ }^{4}$ diagnoses, this paper discusses only the DSM-IV diagnoses. The K-CIDI was validated by Cho et al. ${ }^{3}$ according to the World Health Organization (WHO) guidelines. ${ }^{7}$ The K-CIDI 2.1 was also used in the 2001 KECA and the 2006 KECA-R, both of which were national psychiatric epidemiological surveys.

A total of 78 interviewers recruited from each catchment area received a 5-day training session according to the standard protocols and training materials developed by the WHO.

\section{Statistical analysis}

Weights were calculated for the respondents and used to adjust the data to approximate the national age and sex distributions according to the 2010 census. ${ }^{5}$ All statistical analyses were based on the weighted data. Multivariate logistic regression was performed to determine the demographic correlates of MDD and alcohol use disorders. Statistical significance was set at $\mathrm{p}<0.05$, and all analyses were performed using SPSS 18.0 for Windows. 


\section{RESULTS}

\section{Subjects characteristics}

A total of 6,022 subjects completed the interview, and 1,628 refused (response rate: $78.7 \%$ ). Table 1 presents the demographic profile of the sample.

\section{Prevalence of mental disorders}

Lifetime and 12-month prevalence rates of major DSM-IV mental disorders are shown in Table 2 along with their corresponding standard errors (SEs). More than one-quarter (27.6\%) of respondents had experienced at least one DSM-IV mental disorder before being interviewed. Excluding nicotine

Table 1. Demographic characteristics of the subjects: the KECA2011 study

\begin{tabular}{|c|c|c|}
\hline & \multicolumn{2}{|c|}{ Total $(\mathrm{N}=6022)$} \\
\hline & Unweighted, N (\%) & Weighted* (\%) \\
\hline \multicolumn{3}{|l|}{ Gender } \\
\hline Female & $3714(61.7)$ & 50.1 \\
\hline Male & $2308(38.3)$ & 49.9 \\
\hline \multicolumn{3}{|l|}{ Age (years) } \\
\hline $18-29$ & $837(13.9)$ & 22.1 \\
\hline $30-39$ & $1191(19.8)$ & 21.6 \\
\hline $40-49$ & $1177(19.5)$ & 22.7 \\
\hline $50-59$ & $1195(19.8)$ & 18.2 \\
\hline $60-69$ & $1025(17.0)$ & 11.1 \\
\hline $70-74$ & $596(9.9)$ & 4.3 \\
\hline \multicolumn{3}{|l|}{ Marital state } \\
\hline Married & $3917(65.0)$ & 61.1 \\
\hline NLWP & $1026(17.0)$ & 12.0 \\
\hline Unmarried & 1075 (17.9) & 26.8 \\
\hline \multicolumn{3}{|l|}{ Education (years) } \\
\hline Not educated & $235(3.9)$ & 1.9 \\
\hline $1-6$ & $902(15.0)$ & 9.5 \\
\hline $7-9$ & $714(11.9)$ & 9.8 \\
\hline $10-12$ & $2010(33.4)$ & 35.3 \\
\hline$\geq 13$ & $2161(35.9)$ & 43.4 \\
\hline \multicolumn{3}{|l|}{ Employment } \\
\hline Full-time & $3928(65.4)$ & 63.9 \\
\hline Part-time & $386(6.4)$ & 6.5 \\
\hline Unemployed & $1694(28.2)$ & 29.6 \\
\hline \multicolumn{3}{|l|}{ District } \\
\hline Urban & $4687(77.8)$ & 79.5 \\
\hline Rural & $1335(22.2)$ & 20.5 \\
\hline
\end{tabular}

*weighted by age and sex to the general population of South Korea. KECA: Korean Edipemiologic Catchment Area, NLWP: not living with partner, or separated/divorced/widowed use disorders, the lifetime prevalence of all DSM-IV mental disorders was $24.7 \%$. When both nicotine and alcohol use disorders were excluded, the prevalence of all DSM-IV mental disorders decreased to $14.4 \%$.

In terms of lifetime prevalence, alcohol use disorders were the most prevalent (13.4\%), followed by anxiety disorders (8.7\%), mood disorders (7.5\%), and nicotine use disorders (7.2\%). Alcohol use disorders were the most common lifetime diagnoses among men (20.7\%), and anxiety disorders were the most common lifetime diagnoses (12.0\%) among women.

During the 12 months before the survey, $16.0 \%$ of the subjects had suffered from more than one DSM-IV mental disorder. Anxiety disorders (6.8\%) were most frequently reported, followed by alcohol use disorders (4.4\%), nicotine use disorders $(4.0 \%)$, and mood disorders (3.6\%). Nicotine use disorders $(7.0 \%)$ were the most common among men, and anxiety disorders $(9.8 \%)$ were the most common among women.

\section{Demographic correlates}

Adjusted odds ratios of lifetime and 12-month prevalence rates of mood disorders, anxiety disorders, and alcohol use disorders were calculated by demographic characteristics (Table 3). Because these mental disorders were the most prevalent among Korean adults, they were included for further logistic regression analyses, which were adjusted for various demographic characteristics.

According to the bivariate analyses, being female; young; divorced, separated, or widowed (div/sep/wid); and in a lowincome group (<2000 USD) were associated with an increased risk for both lifetime and 12-month prevalence rates of mood disorders, and also for the lifetime prevalence of anxiety disorders. In contrast, the lifetime and 12-month prevalence rates of alcohol use disorders decreased as a function of age, and being male was associated with the prevalence of alcohol use disorders. Marital status and monthly income were not related to the prevalence of alcohol use disorders, whereas having less education ( $<12$ years) was significantly correlated with the 12-month prevalence of alcohol use disorders.

\section{DISCUSSION}

The prevalence of major mental disorders was as high in Korea as in other developed countries. More than one-quarter (27.6\%) of the subjects had experienced at least one DSM-IV mental disorder in their lifetime.

We compared the results of this study with those of a previous national epidemiologic study conducted in $2006 .{ }^{1}$ The 12 -month prevalence of any mental disorder, excluding those involving nicotine and alcohol use, increased from $9.1 \%$ in 
MJ Cho et al.

Table 2. Lifetime and 12-month prevalence* of DSM-IV major mental disorders in South Korea (weightedt)

\begin{tabular}{|c|c|c|c|c|c|c|}
\hline \multirow{2}{*}{ Diagnoses } & \multicolumn{3}{|c|}{ Lifetime } & \multicolumn{3}{|c|}{ 12-month } \\
\hline & Male & Female & Total & Male & Female & Total \\
\hline Alcohol use disorders & $20.7(1.0)$ & $6.1(0.6)$ & $13.4(0.9)$ & $6.6(0.6)$ & $2.1(0.4)$ & $4.4(0.5)$ \\
\hline Alcohol dependence & $7.6(0.7)$ & $3.1(0.4)$ & $5.3(0.6)$ & $3.2(0.4)$ & $1.2(0.3)$ & $2.2(0.4)$ \\
\hline Alcohol abuse & $13.0(0.8)$ & $3.1(0.4)$ & $8.0(0.7)$ & $3.4(0.5)$ & $0.9(0.2)$ & $2.1(0.4)$ \\
\hline Nicotine use disorders & $12.7(0.8)$ & $1.7(0.3)$ & $7.2(0.7)$ & $7.0(0.6)$ & $0.9(0.2)$ & $4.0(0.5)$ \\
\hline Nicotine dependence & $9.6(0.7)$ & $1.4(0.3)$ & $5.5(0.6)$ & $5.5(0.6)$ & $0.7(0.2)$ & $3.1(0.4)$ \\
\hline Nicotine withdrawal & $5.2(0.6)$ & $0.9(0.2)$ & $3.1(0.4)$ & $2.7(0.4)$ & $0.4(0.2)$ & $1.6(0.3)$ \\
\hline Psychotic disorders & $0.3(0.1)$ & $0.9(0.2)$ & $0.6(0.2)$ & $0.2(0.1)$ & $0.5(0.2)$ & $0.4(0.2)$ \\
\hline Schizophrenia & $0.1(0.1)$ & $0.2(0.1)$ & $0.1(0.1)$ & $0.1(0.1)$ & $0.1(0.1)$ & $0.1(0.1)$ \\
\hline Schizophreniform disorder & $0.1(0.1)$ & $0.0(0.0)$ & $0.0(0.0)$ & $0.1(0.1)$ & - & $0.0(0.0)$ \\
\hline Schizoaffective disorder & - & $0.0(0.0)$ & $0.0(0.0)$ & - & - & - \\
\hline Delusional disorder & - & - & - & - & - & - \\
\hline Brief psychotic disorder & $0.1(0.1)$ & $0.6(0.2)$ & $0.4(0.2)$ & $0.1(0.1)$ & $0.4(0.2)$ & $0.2(0.1)$ \\
\hline Mood disorders & $4.8(0.5)$ & $10.1(0.8)$ & $7.5(0.7)$ & $2.3(0.4)$ & $4.9(0.5)$ & $3.6(0.5)$ \\
\hline Major depressive disorder & $4.3(0.5)$ & $9.1(0.7)$ & $6.7(0.6)$ & $1.8(0.3)$ & $4.3(0.5)$ & $3.1(0.4)$ \\
\hline Dysthymic disorder & $0.4(0.2)$ & $1.2(0.3)$ & $0.8(0.2)$ & $0.3(0.1)$ & $0.6(0.2)$ & $0.4(0.2)$ \\
\hline Bipolar disorder & $0.2(0.1)$ & $0.2(0.1)$ & $0.2(0.1)$ & $0.2(0.1)$ & $0.2(0.1)$ & $0.2(0.1)$ \\
\hline Anxiety disorders & $5.3(0.6)$ & $12.0(0.8)$ & $8.7(0.7)$ & $3.7(0.5)$ & $9.8(0.8)$ & $6.8(0.6)$ \\
\hline Obsessive-compulsive disorder & $0.5(0.2)$ & $1.0(0.3)$ & $0.7(0.2)$ & $0.3(0.1)$ & $0.8(0.2)$ & $0.6(0.2)$ \\
\hline Posttraumatic stress disorder & $1.0(0.3)$ & $2.1(0.4)$ & $1.6(0.3)$ & $0.3(0.1)$ & $0.9(0.2)$ & $0.6(0.2)$ \\
\hline Panic disorder & $0.1(0.1)$ & $0.4(0.2)$ & $0.3(0.1)$ & - & $0.3(0.1)$ & $0.2(0.1)$ \\
\hline Agoraphobia & $0.2(0.1)$ & $0.6(0.2)$ & $0.4(0.2)$ & $0.2(0.1)$ & $0.3(0.1)$ & $0.3(0.1)$ \\
\hline Social phobia & $0.4(0.2)$ & $0.6(0.2)$ & $0.5(0.2)$ & $0.3(0.1)$ & $0.4(0.2)$ & $0.3(0.1)$ \\
\hline Generalized anxiety disorder & $1.4(0.3)$ & $2.4(0.4)$ & $1.9(0.3)$ & $0.8(0.2)$ & $1.2(0.3)$ & $1.0(0.3)$ \\
\hline Specific phobia & $2.7(0.4)$ & $7.8(0.7)$ & $5.2(0.6)$ & $2.4(0.4)$ & $7.2(0.7)$ & $4.8(0.5)$ \\
\hline Any DSM-IV disorder ${ }^{\ddagger}$ & $31.7(1.2)$ & $23.5(1.1)$ & $27.6(1.1)$ & $16.2(0.9)$ & $15.8(0.9)$ & $16.0(0.9)$ \\
\hline $\begin{array}{l}\text { Any DSM-IV disorder except for } \\
\text { nicotine use disorders }\end{array}$ & $26.4(1.1)$ & $23.0(1.1)$ & $24.7(1.1)$ & $11.5(1.8)$ & $15.5(0.9)$ & $13.5(0.9)$ \\
\hline $\begin{array}{l}\text { Any DSM-IV disorder except for } \\
\text { substance use disorders }\end{array}$ & $9.2(0.7)$ & $19.6(1.0)$ & $14.4(0.9)$ & $6.1(0.6)$ & $14.3(0.9)$ & $10.2(0.8)$ \\
\hline
\end{tabular}

${ }^{*}$ values are given as \% (SE), ${ }^{\dagger}$ weighted by age and sex to the general population of South Korea, ${ }^{\text {*including alcohol use disorders, nicotine use }}$ disorders, psychotic disorders, mood disorders and anxiety disorders. DSM-IV: Diagnostic and Statistical Manual of Mental Disorders, Fourth Edition

2006 to $10.2 \%$ in 2011 . However, the prevalence of nicotine and alcohol use disorders declined substantially. Thus, the overall prevalence of all DSM-IV mental disorders, including nicotine and alcohol use disorders, decreased among community residents aged 18-64 years from $19.0 \%$ in $2001^{2}$ and $16.9 \%$ in $2006^{1}$ to $16.2 \%$ in 2011 .

\section{Mood disorders}

The 12-month prevalence of major depressive disorder increased from $1.8 \%$ in $2001^{2}$ and $2.5 \%$ in $2006^{1}$ to $3.1 \%$ in 2011. This increased prevalence of MDD may be associated with the high suicide rate in Korea, which increased dramati- cally between 1992 (8.3 per 100,000 individuals) and 2010 (31.2 per 100,000 individuals). However, the prevalence of dysthymic disorder and bipolar disorder remained relatively stable during this period.

In general, depressive disorder is less frequently reported in Asian countries than in countries with European ancestry: it was $2.2 \%$ in China, ${ }^{8} 2.9 \%$ in Japan, ${ }^{9} 9.6 \%$ in the US, ${ }^{10}$ and $5.2 \%$ in the Netherlands. ${ }^{11}$ Chang et al. ${ }^{12}$ suggested that the low prevalence of depression in Korea may be due to Koreans' use of a higher threshold for what constitutes a depressed mood. Although the prevalence of MDD in Korea remains lower than it is in Western countries, the prevalence of MDD 
Table 3. Adjusted odds ratio $(\mathrm{AOR})^{\dagger}$ and $95 \%$ confidence interval $(\mathrm{Cl})$ of lifetime and 12-month mood disorder, anxiety disorder, and alcohol use disorder by demographic characteristics (weighted ${ }^{\ddagger}$ )

\begin{tabular}{|c|c|c|c|c|c|c|}
\hline \multirow[b]{2}{*}{ Characteristics } & \multicolumn{3}{|c|}{ Lifetime } & \multicolumn{3}{|c|}{ 12-month } \\
\hline & Mood disorder & Anxiety disorder & $\begin{array}{c}\text { Alcohol use } \\
\text { disorder }\end{array}$ & Mood disorder & Anxiety disorder & $\begin{array}{c}\text { Alcohol use } \\
\text { disorder }\end{array}$ \\
\hline \multicolumn{7}{|l|}{ Gender } \\
\hline Male & 1.0 & 1.0 & 1.0 & 1.0 & 1.0 & 1.0 \\
\hline Female & $2.1(1.7-2.7)^{* * *}$ & $2.3(1.9-2.9)^{* * *}$ & $0.2(0.2-0.3)^{* * *}$ & $1.7(1.2-2.3)^{* *}$ & $2.5(2.0-3.2)^{* * *}$ & $0.3(0.2-0.4)^{* * *}$ \\
\hline \multicolumn{7}{|l|}{ Age, year } \\
\hline $18-39$ & 1.0 & 1.0 & 1.0 & 1.0 & 1.0 & 1.0 \\
\hline $40-59$ & $0.9(0.7-1.3)$ & $0.8(0.6-1.1)$ & $0.6(0.5-0.8)^{* * *}$ & $0.8(0.5-1.2)$ & $0.7(0.6-1.0)^{*}$ & $0.6(0.4-0.8)^{* *}$ \\
\hline $60-74$ & $0.6(0.4-0.9)^{*}$ & $0.5(0.4-0.8)^{* *}$ & $0.3(0.2-0.5)^{* * *}$ & $0.5(0.3-0.9)^{*}$ & $0.5(0.3-0.8)^{* *}$ & $0.2(0.1-0.5)^{* * *}$ \\
\hline \multicolumn{7}{|l|}{ Place of residence } \\
\hline Urban & 1.0 & 1.0 & 1.0 & 1.0 & 1.0 & 1.0 \\
\hline Rural & $1.1(0.8-1.4)$ & $0.9(0.7-1.1)$ & $1.1(0.9-1.4)$ & $1.0(0.7-1.5)$ & $0.8(0.6-1.0)$ & $1.0(0.7-1.4)$ \\
\hline \multicolumn{7}{|l|}{ Education } \\
\hline Low (<12 years) & 1.0 & 1.0 & 1.0 & 1.0 & 1.0 & 1.0 \\
\hline High ( $\geq 13$ years) & $0.8(0.7-1.1)$ & $1.0(0.8-1.2)$ & $0.9(0.8-1.1)$ & $0.7(0.5-1.1)$ & $0.9(0.7-1.2)$ & $0.7(0.5-1.0)^{*}$ \\
\hline \multicolumn{7}{|l|}{ Marital status } \\
\hline Married & 1.0 & 1.0 & 1.0 & 1.0 & 1.0 & 1.0 \\
\hline Div/Sep/Wid & $2.3(1.7-3.1)^{* * *}$ & $1.7(1.2-2.3)^{* * *}$ & $1.3(1.0-1.8)$ & $2.0(1.3-3.1)^{* * *}$ & $1.4(1.0-2.0)$ & $1.1(0.6-1.8)$ \\
\hline Not married & $1.4(1.1-2.0)^{*}$ & $1.4(1.1-1.8)^{*}$ & $0.8(0.7-1.1)$ & $1.2(0.8-2.0)$ & $1.4(1.0-1.8)$ & $0.9(0.6-1.8)$ \\
\hline \multicolumn{7}{|l|}{ Monthly income } \\
\hline Low $(<2000$ USD) & $1.6(1.3-2.1)^{* * *}$ & $1.8(1.4-2.2)^{* * *}$ & $1.1(0.9-1.3)$ & $2.4(1.7-3.4)^{* * *}$ & $1.8(1.4-2.3)^{* * *}$ & $0.9(0.7-1.3)$ \\
\hline High ( $\geq 2000$ USD) & 1.0 & 1.0 & 1.0 & 1.0 & 1.0 & 1.0 \\
\hline
\end{tabular}

has increased as industrialization and Westernization have progressed. Increased stress and rapid sociocultural change may affect vulnerability to mood disorders. Additionally, as public knowledge about MDD has advanced, Korean individuals may be more amenable to acknowledging depressive symptoms.

Whereas being female or separated/divorced was associated with the 12-month prevalence of MDD in the adjusted logistic regression model used in the 2001 survey, $^{2}$ being younger and in a low-income group were added as correlates of MDD in this 2011 survey. This change suggests that more attention should be devoted to the mental health of members of the younger generation who are unemployed or have a low income.

\section{Anxiety disorders}

The 12-month prevalence of anxiety disorders also increased, from $5.0 \%$ in $2006^{1}$ to $6.8 \%$ in 2011 . This prevalence is higher than that in other East Asian countries $(2.7 \%$ in metropolitan areas of $\mathrm{China}^{8}$ and $4.8 \%$ in $\operatorname{Japan}^{9}$ ), but it is much lower than it is in Western countries (12.0\% in France, ${ }^{10}$
$18.2 \%$ in the US, ${ }^{10}$ and $10.1 \%$ in the Netherlands). Obsessivecompulsive disorder, which had a prevalence of $0.6 \%$ in this study, was not treated as an anxiety disorder in the WHOWorld Mental Health studies of Japan and China and in the Netherlands. ${ }^{10,11}$

Moreover, as some kinds of anxiety disorders are strongly influenced by the sociocultural environment, their prevalence in Korea and Western countries may differ substantially. For example, the prevalence of social phobia was $0.4 \%$ in this study, whereas it was $7.1 \%$ in the NCS-R, ${ }^{10} 6.8 \%$ in the US, ${ }^{10}$ $1.7 \%$ in France, ${ }^{10}$ and $3.8 \%$ in the Netherlands. ${ }^{11}$

\section{Nicotine and alcohol use disorders}

The prevalence of both nicotine and alcohol use disorders has been decreasing. The 12-month prevalence of nicotine dependence decreased from $6.0 \%$ in $2001^{2}$ and $5.1 \%$ in $2006^{1}$ to $3.2 \%$ in 2011 . This dramatic change may be attributable to the government's anti-smoking policies and the negative social attitudes toward smokers.

Similarly, the 12-month prevalence of alcohol use disorders also dropped markedly, from $6.8 \%$ in $2001^{2}$ and $5.6 \%$ in $2006^{1}$ 
to $4.4 \%$ in 2011 ; however, it was still much higher than that in China $(1.6 \%)^{8}$ and Japan (0.5\%). ${ }^{9}$ Moreover, this prominent reduction in alcohol use disorders has been evident only in males (25.2\% in 2001, ${ }^{2} 25.5 \%$ in $2006,{ }^{1}$ and $20.7 \%$ in 2011$)$; in women, the prevalence has remained relatively stable $(6.3 \%$ in $2001,{ }^{2} 6.9 \%$ in $2006,{ }^{1}$ and $6.1 \%$ in 2011 . As a result, the male to female ratio in the prevalence of alcohol use disorders declined from 4.4 in $2001^{2}$ and 3.7 in $2006^{1}$ to 3.4 in 2011.

This result may also be attributable to a change in the sociocultural environment. The traditionally permissive attitudes in Korea toward alcohol-related problems in males have shifted toward a disapproving view that treats these as "maladaptive patterns of alcohol use." ${ }^{13}$ In contrast, negative attitudes toward alcohol consumption by females have been reduced as more women have entered the workplace.

Being male and younger were associated with alcohol use disorders in the 2001 survey. $^{2}$ However, although high income was an important correlate of alcohol use disorders in 2001 (AOR 1.7), ${ }^{2}$ economic status was no longer associated with these disorders in 2011. We can assume that the reduced prevalence of alcohol use disorders applies to those with high incomes and not to those with low incomes.

\section{Psychotic disorders}

The lifetime prevalence of schizophrenia in this study was $0.1 \%$, which is same as in the previous studies in $2001^{2}$ and 2006. ${ }^{1}$ However, the prevalence of schizophrenia in a community sample may be underestimated for several reasons. Psychotic disorders tend to be underreported in community samples as the social stigma and cognitive decline related to psychotic disorders can interfere with reports about psychotic symptoms or cause patients to refuse study participation. Additionally, the psychosis module of the CIDI has good specificity but poor sensitivity. ${ }^{14}$ As schizophrenia is very similar to schizophreniform and schizoaffective disorders, schizophrenia may have been misdiagnosed as one of the other two disorders. Even when the CIDI can make this differential diagnosis, it can be hard for lay interviewers to distinguish the disorders from one another. When the rates of schizophreniform and schizoaffective disorders was added to that of schizophrenia the prevalence increased to $0.2 \%$.

Additionally, institutionalized individuals were not included in this study. If institutionalized patients with schizophrenia had been included, the prevalence may have increased to $0.3 \%$, which is similar to the prevalence of this disorder according other national studies. The lifetime combined prevalence of schizophrenia, schizoaffective disorder, and schizophreniform disorder was $0.37 \%$ in the Netherlands, ${ }^{15,16}$ and the prevalence of schizophrenia was $0.4 \%$ in a Chinese rural area. ${ }^{17}$ In their systematic review Saha et al. ${ }^{18}$ reported that the median lifetime prevalence of schizophrenia was $0.4 \%$.

\section{Limitations}

This study has several limitations, including its cross-sectional sectional design. Additionally, non-respondents may have affected the prevalence rates of mental disorders as it has been reported that non-respondents tend to have higher rates of mental disorders than do respondents. ${ }^{19,20}$ Indeed, individuals with severe mental disorders may have found it more difficult to complete the survey due to the symptoms of their specific disorder or related cognitive difficulties. Thus, more severe disorders may have been underreported compared with less severe disorders.

Moreover, recall bias may have influenced the results as respondents, especially elderly individuals with cognitive impairment, may forget or underestimate their symptoms.

\section{Conclusion}

This study examined the prevalence and correlates of major mental disorders in Korea and compared them with comparable data from previous surveys. We found that major mental disorders were highly prevalent in Korea. More than onequarter of the subjects had experienced at least one DSM-IV mental disorder in their lifetime. Although the prevalence of nicotine and alcohol use disorders has decreased, they remained more prevalent in Korea than in Japan or China, and the decreasing trend was not observed in women. The prevalence of MDD has increased and is now similar to that in Japan, but it remains lower than that in Western countries. Conversely, anxiety disorders have become more prevalent in Korea than in other East Asian countries, but this rate was also much lower than that in Western countries.

\section{Acknowledgments}

This study was funded by the Korean Ministry of Health and Welfare, which had no role in study design; the collection, analysis, and interpretation of data; the writing of the report; or the decision to submit the paper for publication. The authors wish to express their gratitude to the 78 interviewers and to the subjects who completed the interview.

\section{REFERENCES}

1. Cho MJ, Chang SM, Lee YM, Bae A, Ahn JH, Son J, et al. Prevalence of DSM-IV major mental disorders among Korean adults: a $2006 \mathrm{Na}$ tional Epidemiologic Survey (KECA-R). Asian J Psychiatr 2010;3:2630.

2. Cho MJ, Kim JK, Jeon HJ, Suh T, Chung IW, Hong JP, et al. Lifetime and 12-month prevalence of DSM-IV psychiatric disorders among Korean adults. J Nerv Ment Dis 2007;195:203-210.

3. Cho MJ HB, Suh DW, Hong JP, Bae JN, Kim JK, Lee DW, Cho SJ. Development of a Korean version of the Composite International Diagnostic Interview (K-CIDI). J Korean Neuropsychiatr Assoc 2002;41:123137.

4. American Psychiatric Association. Diagnostic and Statistical Manual of Mental Disorders, 4th Edition. Washington, DC: American Psychiatric 
Press; 1994.

5. Korea National Statistical Office. 2010 Population and Housing Census Report. Daejeon, Korea: Korea National Statistical Office; 2011.

6. World Health Organization, 1990. Composite International Diagnostic Interview (CIDI), Version 1.0. Geneva, Switzerland: World Health Organization; 1990.

7. World Health Organization. Procedures for the Development of New Language Versions of the WHO Composite International Diagnostic Interview (WHO-CIDI). Geneva, Switzerland: World Health Organization; 1997.

8. Shen YC, Zhang MY, Huang YQ, He YL, Liu ZR, Cheng H, et al. Twelve-month prevalence, severity, and unmet need for treatment of mental disorders in metropolitan China. Psychol Med 2006;36:257-267.

9. World Mental Health Survey in Japan. Available at: http://www.ncnp. go.jp/nimh/keikaku/epi/result.html. Accessed November 17, 2012.

10. Demyttenaere K, Bruffaerts R, Posada-Villa J, Gasquet I, Kovess V, Lepine JP, et al. Prevalence, severity, and unmet need for treatment of mental disorders in the World Health Organization World Mental Health Surveys. JAMA 2004;291:2581-2590.

11. de Graaf R, Ten Have M, van Gool C van Dorsselaer S. [Prevalence of mental disorders, and trends from 1996 to 2009. Results from NEMESIS-2]. Tijdschr Psychiatr 2012;54:27-38.

12. Chang SM, Hahm BJ, Lee JY, Shin MS, Jeon HJ, Hong JP, et al. Crossnational difference in the prevalence of depression caused by the diagnostic threshold. J Affect Disord 2008;106:159-167.
13. Hahm BJ, Cho MJ. Prevalence of alcohol use disorder in a South Korean community--changes in the pattern of prevalence over the past 15 years. Soc Psychiatry Psychiatr Epidemiol 2005;40:114-119.

14. Cooper L, Peters L, Andrews G. Validity of the Composite International Diagnostic Interview (CIDI) psychosis module in a psychiatric setting. J Psychiatr Res 1998;32:361-368.

15. Bijl RV, Ravelli A, van Zessen G. Prevalence of psychiatric disorder in the general population: results of The Netherlands Mental Health Survey and Incidence Study (NEMESIS). Soc Psychiatry Psychiatr Epidemiol 1998;33:587-595.

16. van Os J, Hanssen M, Bijl RV, Vollebergh W. Prevalence of psychotic disorder and community level of psychotic symptoms: an urban-rural comparison. Arch Gen Psychiatry 2001;58:663-668.

17. Ran MS, Xiang MZ, Li SX, Shan YH, Huang MS, Li SG, et al. Prevalence and course of schizophrenia in a Chinese rural area. Aust N Z J Psychiatry 2003;37:452-457.

18. Saha S, Chant D, Welham J, McGrath J. A systematic review of the prevalence of schizophrenia. PLoS Med 2005;2:e141.

19. de Graaf R, Bijl RV, Smit F, Ravelli A, Vollebergh WA. Psychiatric and sociodemographic predictors of attrition in a longitudinal study: The Netherlands Mental Health Survey and Incidence Study (NEMESIS). Am J Epidemiol 2000;152:1039-1047.

20. Eaton WW, Anthony JC, Tepper S, Dryman A. Psychopathology and attrition in the epidemiologic catchment area surveys. Am J Epidemiol 1992;135:1051-1059. 